\title{
Gastric Perforation
}

National Cancer Institute

\section{Source}

National Cancer Institute. Gastric Perforation. NCI Thesaurus. Code C78316.

A rupture in the gastric wall caused by traumatic or pathologic processes. 